\title{
Impact of Sclerotinia Stem Rot on Yield of Canola
}

L. E. del Río and C. A. Bradley, Department of Plant Pathology, North Dakota State University, Fargo 58105; R. A. Henson and G. J. Endres, Carrington Research Extension Center, North Dakota State University, Carrington 58421; B. K. Hanson, Langdon Research Extension Center, North Dakota State University, Langdon 58249; K. McKay and M. Halvorson, North Central Research Extension Center, North Dakota State University, Minot 58701; P. M. Porter and D. G. Le Gare, Department of Agronomy and Plant Genetics, University of Minnesota, St. Paul 55108; and H. A. Lamey, Department of Plant Pathology, North Dakota State University, Fargo

\begin{abstract}
del Río, L. E., Bradley, C. A., Henson, R. A., Endres, G. J., Hanson, B. K., McKay, K., Halvorson, M., Porter, P. M., Le Gare, D. G., and Lamey, H. A. 2007. Impact of Sclerotinia stem rot on yield of canola. Plant Dis. 91:191-194.

Sclerotinia sclerotiorum is the causal agent of Sclerotinia stem rot (SSR) of canola (Brassica napus). In North Dakota, the leading canola producer in the United States, SSR is an endemic disease. In order to estimate the impact of this disease on canola yield, field experiments were conducted from 2000 to 2004 at several locations in North Dakota and Minnesota. Experimental plots were either inoculated with laboratory-produced ascospores or infected by naturally occurring inoculum in commercial fields. Applying fungicides at different concentrations and timings during the flowering period created epiphytotics of diverse intensities. Disease incidence was measured once prior to harvesting the crop on 50 to 100 plants per plot. Results of the study indicated that $0.5 \%$ of the potential yield (equivalent to $12.75 \mathrm{~kg} / \mathrm{ha}$ ) was lost for every unit percentage of SSR incidence (range of 0.18 to $0.96 \%$ ). Considering the current cost of fungicide applications and the market value of this commodity, a 17\% SSR incidence could cause losses similar to the cost of a fungicide application. Additional efforts are required to improve current levels of tolerance of canola plants to this pathogen.
\end{abstract}

More than $90 \%$ of the canola (Brassica napus L.) planted in the United States is located in North Dakota. In 2004, approximately 300,000 ha were planted in this state, with an estimated production of 5.54 $\times 10^{5}$ metric tons and a projected market value of over US\$135.7 million (11). The area planted to canola increased to 420,875 ha in 2005, and is expected to grow even more in the near future due to increased demand from the biodiesel industry.

Sclerotinia stem rot (SSR), caused by Sclerotinia sclerotiorum (Lib.) de Bary, is one of the two major fungal diseases affecting canola production in North Dakota. Currently, the disease is managed mainly through the use of fungicides and crop rotations because there are no commercially available resistant cultivars $(2,19)$. SSR is endemic in the state, with an annual average incidence of $13.6 \%(3,14)$, and a direct economic impact estimated at US\$94 million for the period between 1991 and 2002 (14).

In spite of its importance, the relationship between SSR and yield of canola

\section{Corresponding author: L. del Río \\ E-mail: luis.delrio-mendoza@ndsu.edu}

Accepted for publication 19 September 2006.

DOI: 10.1094/PDIS-91-2-0191

(C) 2007 The American Phytopathological Society plants has not been characterized recently. The only published estimates available were produced more than 20 years ago for growing conditions of the province of Alberta, Canada (16). More recently, Bradley et al. (2) reported on the response of 19 cultivars to SSR under greenhouse and field conditions, and on the efficacy of fungicides to manage SSR using a number of cultivars across several locations and years (4). However, neither of them explored the relationship between SSR and yield. An estimation of the impact of SSR on yield of canola would not only result in a more accurate assessment of the economic impact of this important disease but also help growers determine the necessity for fungicide applications. Thus, the objective of this study was to get a better estimate of the relationship between SSR and yield of modern canola cultivars under growing conditions in North Dakota and Minnesota and provide the information necessary to establish economic thresholds to manage this disease.

\section{MATERIALS AND METHODS}

The relationship between SSR incidence and yield of canola was evaluated using three sets of data collected in field studies. The first data set was collected from replicated experiments conducted in commercial fields between 2000 and 2001 in Langdon and Newburg, ND. The second data set was collected from 12 replicated field experiments conducted at North Dakota State University (NDSU) Research Extension Centers in Langdon, Carrington, and Minot, ND and at a University of Minnesota research site in Red Lake Falls, MN from 2000 to 2004. All experimental plots ranged in size from 7.4 to $13.7 \mathrm{~m}^{2}$ and were laid out using a randomized complete block design with four replications. SSR epiphytotics developed in experimental plots of the first data set from naturally occurring inoculum. Experimen-

Table 1. Fungicide treatments applied to canola plots at several locations in North Dakota and Minnesota from 2000 to 2004

\begin{tabular}{lcccccc}
\hline & \multicolumn{5}{c}{ Years $^{\mathbf{a}}$} \\
\cline { 3 - 7 } Fungicide treatments $^{\mathbf{b}}$ & Rate $(\mathbf{g}$ a.i./ha) & $\mathbf{2 0 0 0}$ & $\mathbf{2 0 0 1}$ & $\mathbf{2 0 0 2}$ & $\mathbf{2 0 0 3}$ & $\mathbf{2 0 0 4}$ \\
\hline Untreated control & $\ldots$ & + & + & + & + & + \\
Azoxystrobin & 175 & + & + & - & - & - \\
Benomyl & $489-561$ & + & + & - & - & - \\
Boscalid & $200-299$ & + & + & + & + & + \\
Fluazinam & $248-496$ & + & - & - & - & - \\
Iprodione & 504 & + & + & + & + & - \\
Pentachloronitrobenzene & 1,680 & - & - & - & + & + \\
Prothioconazole & $151-200$ & - & - & + & + & + \\
Tebuconazole & $126-190$ & + & + & - & - & - \\
Thiophanate-methyl & 785 & - & + & + & + & + \\
Trifloxystrobin & $175-245$ & + & - & - & - & - \\
Vinclozolin & $375-420$ & + & + & + & + & + \\
V-10116 & $134-141$ & - & - & - & + & + \\
\hline
\end{tabular}

a Compound evaluated (+) or not evaluated (-) that year. Experiments were conducted at two locations in 2000, six locations in 2001, one location in 2002, four locations in 2003, and three locations in 2004. Experiments at each location had four replications.

b Fungicides were applied between 10 and 50\% flowering period. 
tal plots from the second data set were inoculated with $10^{4}$ ascospores $\mathrm{ml}^{-1}$ at the beginning of the flowering period.

Fungicides were applied to naturally and artificially inoculated plots when plants reached the $20,30,40$, or $50 \%$ flowering stage. The variety of fungicides used and the different concentrations applied (Table 1) created SSR epiphytotics of diverse intensity. Fungicides were applied using $\mathrm{CO}_{2}$-pressurized backpack sprayers, which delivered them in water at a rate of 131 to 188 liters ha ${ }^{-1}$. Fungicide-free plots (negative controls) were included in each location and year in both data sets, but positive control plots (noninoculated but sprayed with fungicides) were not included. Agronomic management of plots located in commercial fields was conducted using standard commercial equipment. All experimental plots were managed following commercial standard production practices. SSR incidence in all experiments was recorded at physiological maturity by reading 100 plants in each plot. The response of SSR and canola to the fungicides applied has been reported (4).

The third data set was collected in experiments that evaluated the reaction of 16 to 18 different commercial cultivars to artificial inoculations with $S$. sclerotiorum at $10^{3}$ ascospores $\mathrm{ml}^{-1}$ between 2001 and
2004. Experimental plots were established at the NDSU Research Extension Center at Carrington, ND and a University of Minnesota on-farm site near Red Lake Falls, MN. Each experimental plot was $6.5 \mathrm{~m}^{2}$ in size and was planted to a density of 1.7 million seed $\mathrm{ha}^{-1}$ at Carrington; whereas, at Red Lake Falls, plots were $9 \mathrm{~m}^{2}$ in size and planted at a density of 1.5 million seed $\mathrm{ha}^{-1}$. Plots at both locations were inoculated with ascospores at the beginning of the flowering period and then mist irrigated to stimulate disease development. Disease incidence was quantified at physiological maturity by evaluating 50 plants in the middle of each plot. The reaction of these cultivars has been reported elsewhere (2). Of the 18 cultivars evaluated, six cultivars (Pioneer 44A89, Pioneer 46A76, Hyola 357, Hyola 401, Invigor 2663, and LG3455) were planted at both locations in all years. Thus, data collected from these entries were used to characterize the association between SSR incidences and yield. At maturity, experimental plots were cut with a swather and then harvested using small combines.

Statistical analyses. The first two data sets were analyzed by location and year because of the use of different cultivars and differences in disease incidence among locations within years. Analysis of vari- ance of the third data set indicated that the interactions of cultivar-year and locationyear were not significant $(P \leq 0.13)$ for yield, and the interaction of location-yearcultivar was not significant $(P \leq 0.3)$ for SSR incidence (data not shown); thus, data of all six cultivars were pooled across years and locations. All statistical analyses were conducted using the general linear model procedure (PROC GLM) and linear regression analysis (PROC REG) in SAS (SAS Institute, Inc., Cary, NC).

\section{RESULTS}

The use of fungicides at different concentrations and in combination with or without artificial inoculations resulted in the development of SSR epiphytotics of different intensities. Field plots that relied on natural inoculum had disease incidences ranging from 1 to $59 \%$ and the linear models, which explained the association between SSR and yield, indicated that, for every percent of SSR incidence, yield was reduced by an average of 13.13 $\mathrm{kg} / \mathrm{ha}$ (range 10.5 to $15 \mathrm{~kg} / \mathrm{ha}$ ) (Table 2). This level of loss corresponds to a reduction of $0.52 \%$ (range 0.46 to $0.6 \%$ ) of the potential yield for every percent increase of disease incidence. These models all were significant $(P<0.02)$ and explained more than $65 \%$ of the variation observed,

Table 2. Relationship between Sclerotinia stem rot (SSR) incidence and canola yields in inoculated and noninoculated trials in North Dakota during 2000 to 2004

\begin{tabular}{|c|c|c|c|c|c|c|c|}
\hline Year, location & Cultivar & $\begin{array}{c}\text { SSR } \\
\text { inicidence }(\%)\end{array}$ & Intercept & Slope & $R^{2}$ value & Probability & $\begin{array}{c}\text { Reduction of } \\
\text { potential yield }(\%)^{\mathrm{a}}\end{array}$ \\
\hline \multicolumn{8}{|l|}{ Noninoculated trials } \\
\hline 2000, Langdon & Golden Boy & $1-27$ & 2744 & -12.71 & 0.36 & 0.0136 & 0.46 \\
\hline 2001, Langdon & Minot RR & $1-59$ & 2320 & -15.00 & 0.77 & 0.0001 & 0.65 \\
\hline 2001, Newburg & Li-Bred 449 & $8-34$ & 2199 & -10.50 & 0.70 & 0.0182 & 0.48 \\
\hline 2001, Newburg & Pioneer 45A55 & $3-39$ & 2851 & -14.33 & 0.65 & 0.0150 & 0.50 \\
\hline \multicolumn{8}{|l|}{ Inoculated trials } \\
\hline 2000, Langdon & Pioneer 44A89 & $2-17$ & 2793 & -26.83 & 0.62 & 0.0001 & 0.96 \\
\hline 2001, Carrington & Minot RR & $12-94$ & 2290 & -4.10 & 0.22 & 0.0313 & 0.18 \\
\hline 2001, Langdon & Minot RR & $0-14$ & 1972 & -1.11 & 0.00 & 0.8350 & $\ldots$ \\
\hline 2001, Red Lake Falls & Pioneer 45A55 & $9-61$ & 1863 & -6.59 & 0.88 & 0.0194 & 0.35 \\
\hline 2002, Langdon & LG3455 & $9-51$ & 2713 & -10.72 & 0.71 & 0.0003 & 0.40 \\
\hline 2003, Carrington & Hyola 357 Magnum & $44-77$ & 2132 & -6.17 & 0.15 & 0.1439 & $\ldots$ \\
\hline 2003, Langdon & Hyola 357 Magnum & $50-99$ & 3194 & -12.66 & 0.38 & 0.0104 & 0.29 \\
\hline 2003, Minot & Invigor 2663 & $1-8$ & 3092 & -0.24 & 0.00 & 0.9927 & $\ldots$ \\
\hline 2003, Red Lake Falls & Invigor 2663 & $5-25$ & 1905 & -3.27 & 0.03 & 0.5118 & $\ldots$ \\
\hline 2004, Carrington & Hyola 357 Magnum & $1-5$ & 2990 & -20.85 & 0.02 & 0.7601 & $\ldots$ \\
\hline 2004, Langdon & Invigor 2663 & $27-95$ & 2750 & -8.32 & 0.67 & 0.0131 & 0.30 \\
\hline 2004, Red Lake Falls & Invigor 2663 & $0-6$ & 2726 & -0.40 & 0.00 & 0.9869 & $\ldots$ \\
\hline
\end{tabular}

${ }^{a}$ Reduction of potential yield was calculated for experiments with statistically significant $(P \leq 0.05)$ models only as follows: reduction of yield potential $=$ (slope/intercept) $\times 100$.

Table 3. Relationship between Sclerotinia stem rot incidence and yield of six canola cultivars in field trials in North Dakota during 2001 to 2004

\begin{tabular}{|c|c|c|c|c|c|c|}
\hline Cultivar & SSR incidence $(\%)$ & Intercept & Slope & $R^{2}$ value & Probability & Reduction of potential yield $(\%)^{\mathrm{a}}$ \\
\hline Hyola 357 Magnum & $3-61$ & 2592 & -12.79 & 0.26 & 0.0075 & 0.49 \\
\hline Hyola 401 & $1-55$ & 2457 & -10.70 & 0.14 & 0.0616 & 0.43 \\
\hline Invigor 2663 & $2-62$ & 2655 & -15.97 & 0.34 & 0.0013 & 0.60 \\
\hline LG3455 & $1-53$ & 2339 & -15.91 & 0.34 & 0.0013 & 0.68 \\
\hline Pioneer 44A76 & $0-51$ & 2203 & -14.74 & 0.23 & 0.0108 & 0.67 \\
\hline Pioneer 44A89 & $5-90$ & 2209 & -12.09 & 0.40 & 0.0006 & 0.55 \\
\hline Combined & $0-90$ & 2423 & -14.11 & 0.31 & 0.0001 & 0.58 \\
\hline
\end{tabular}

a Reduction of potential yield was calculated for experiments with statistically significant $(P \leq 0.05)$ models only as follows: reduction of yield potential $=$ (slope/intercept) $\times 100$. 
with the exception of an experiment conducted at Langdon, ND in 2000, where the model explained only $36 \%$ of the data variability.

Experimental plots that were artificially inoculated at flowering had SSR incidences ranging from 0 to $99 \%$. However, the disease did not develop in a uniform way across locations and years. In 5 of the 12 experiments, disease incidence did not reach more than $25 \%$ and the models developed were not significant $(P>0.5)$. With the exception of an experiment conducted in 2003 at Carrington, ND, all experiments with disease incidence higher than $25 \%$ produced models that were of statistical significance (Table 2). In these experiments, yield reduction ranged from 4.1 to $26.83 \mathrm{~kg} / \mathrm{ha}$ per each percent of disease incidence, with a mean of 11.54 $\mathrm{kg} / \mathrm{ha}$ per every percent of disease incidence. This value equates to a mean of $0.43 \%$ reduction of the potential yield for every percentage unit of disease incidence. Of the six cultivars from the second data set that produced these models, Minot RR and Pioneer 44A89 had the smallest $(0.18 \%)$ and largest $(0.96 \%)$ rates of potential yield loss, respectively.

Disease incidence for five of the six cultivars in the third data set ranged between 0 and $62 \%$. Pioneer 44A89 was the only cultivar where SSR incidence ranged between 0 and $90 \%$ (Table 3). Statistically significant models that describe the relationship between SSR incidence and yield were produced for all six cultivars. In general, the models indicated that, for every percent disease incidence, the potential yield (intercept value in the regression equation) was reduced by an average of $0.57 \%$ (range 0.43 to $0.68 \%$ ). This percentage of loss of potential yield is equivalent to $13.7 \mathrm{~kg} / \mathrm{ha}$. When a regression analysis was conducted using all data points of the third data set, the resulting model indicated that, for every percent unit of disease incidence, $0.58 \%$ of the potential yield was lost.

\section{DISCUSSION}

Low-intensity SSR epiphytotics developed in 5 of the 12 field experiments from the second data set used for this study. Experimental plots at these locations had disease incidences lower than $25 \%$ in spite of the plots being inoculated with ascospores and the misting systems used to help create appropriate conditions for infection. Temperatures higher than $27^{\circ} \mathrm{C}$ were recorded at these locations for the next several days after inoculation. High ascospore mortality rates have been reported when temperatures like these are combined with high humidity levels (5). In Carrington in 2003, ascospores were inoculated after the $50 \%$ bloom stage in an attempt to escape the warm weather that prevailed at the beginning of the flowering period, which is when infection normally takes place (15). As a result, high disease incidence was recorded, but the ensuing epiphytotic did not develop fast enough as to reduce yields significantly.

SSR incidence was significantly and negatively associated with yield in 10 of the 16 field experiments evaluated in the first two data sets and in data from the third group. Other researchers have detected similar associations between these two variables for diseases caused by $S$. sclerotiorum in dry bean (9) and soybean $(8,18)$. Five of the six experiments where no significant relationship between SSR and yield were detected had SSR incidences $<25 \%$. This lack of association may be an indication that canola plants can compensate for yield under low SSR pressure. Yield compensation at low disease pressure has been postulated for Sclerotinia diseases affecting other crops $(9,12,13,18)$. Relationships other than linear were explored while analyzing the data sets used in this study; however, no significant improvements in the $R^{2}$ values were achieved; thus, in the interest of simplicity, the linear models were adopted. However, additional research may be required to accurately estimate the compensating ability of canola plants.

Yield loss could not be related to disease severity in this study. Disease severity data was recorded simultaneously with incidence; however, the scale used to assess severity was categorical rather than continuous, which prevented it from being used in regression analysis along with a continuous variable. Associating disease severity rather than incidence to yield loss has been the preferred approach by many researchers when foliar diseases are studied $(1,6,7)$; however, unlike foliar pathogens, S. sclerotiorum primarily affects stems and branches of canola plants. As a consequence, plant parts above the infected tissues wilt or die prematurely, a symptom that resembles more the effect of some vascular pathogens or stem canker pathogens $(10,17)$. In this sense, a more accurate estimation of SSR intensity could be achieved if the overall impact of the disease on the plant is evaluated instead of just measuring lesion expansion rates, with multiple readings instead of single observations (20).

Results of this study provide a partial picture of the economic importance of SSR for canola production in the United States. The potential yield of all cultivars evaluated in this study was reduced by an average of $0.5 \%$ (across all data groups), equivalent to $12.75 \mathrm{~kg} / \mathrm{ha}$, for every percent SSR incidence (range of 0.18 to $0.96 \%$ or 4.1 to $26.83 \mathrm{~kg} / \mathrm{ha}$ ). Morral et al. (16), evaluating the response of commercial cultivars planted between 1975 and 1983 in Canada, concluded that losses of potential yield ranged mostly between 0.4 and $0.5 \%$ for each percent increase in SSR incidence. The similarity between findings of Morral and collaborators and ours in relation to the amount of potential yield lost to SSR is an indication that very little progress has been made in the level of tolerance of canola cultivars to SSR, and that this area still has a lot of room for improvement. Further, the impact of the disease on the quality of the canola harvested was not considered here. Additional research is necessary to address this issue. At the current market price of US\$0.24 per kilogram of canola (11), each percent SSR represents a loss of approximately US\$3.06/ha. If we consider that the cost of a fungicide application is approximately US\$50 per ha, a $17 \%$ SSR incidence would be the threshold between monetary loss due to the disease and the cost of a fungicide application. This threshold depends a great deal on yield expectations, market price for the commodity, and the cost of the fungicides and their application. However, weather variables may be an even more important factor. Efforts toward the development of disease-warning systems that include them should be emphasized.

\section{LITERATURE CITED}

1. Bhathal, J. S., Loughman, R., and Speijers, J. 2003. Yield reduction in wheat in relation to leaf disease from yellow (tan) spot and Septoria nodorum blotch. Eur. J. Plant Pathol. 109:435-443.

2. Bradley, C. A., Henson, R. A., Porter, P. M., LeGare, D. G., del Río, L. E., and Khot, S. D. 2006. Response of canola cultivars to Sclerotinia sclerotiorum in controlled and field environments. Plant Dis. 90:215-219.

3. Bradley, C. A., and Lamey, H. A. 2005. Canola disease situation in North Dakota, U.S.A., 1993-2004. Pages 33-34 in: Proc. 14th Aust. Res. Assembly on Brassicas, Port Lincoln, Australia.

4. Bradley, C. A., Lamey, H. A., Endres, G. J., Henson, R. A., Hanson, B. K., McKay, K., Halvorson, M., LeGare, D. G., and Porter, P.M. 2006. Efficacy of fungicides for control of Sclerotinia stem rot of canola. Plant Dis. 90:1129-1134.

5. Caesar, A. J., and Pearson, R. C. 1983. Environmental factors affecting survival of ascospores of Sclerotinia sclerotiorum. Phytopathology 73:1024-1030.

6. Carson, M. L. 2005. Yield loss potential of Phaeosphaeria leaf spot of maize caused by Phaeosphaeria maydis in the United States. Plant Dis. 89:986-988.

7. Danielsen, S., and Munk, L. 2004. Evaluation of disease assessment methods in quinoa for their ability to predict yield loss caused by downy mildew. Crop Prot. 23:219-228.

8. Danielson, G. A., Nelson, B. D., and Helms, T. C. 2004. Effect of Sclerotinia stem rot on yield of soybean inoculated at different growth stages. Plant Dis. 88:297-300.

9. del Río, L. E., Venette, J. R., and Lamey, H. A. 2004. Impact of white mold incidence on dry bean yield under nonirrigated conditions. Plant Dis. 88:1352-1356.

10. Gugel, R. K., and Petrie, G. A. 1992. History, occurrence, impact, and control of blackleg of rapeseed. Can. J. Plant Pathol. 14:36-45.

11. Hartwig, D., and Meyer, B. 2005. North Dakota agricultural statistics 2004. N. D. Agric. Stat. Serv. Fargo.

12. Hoffman, D. D., Hartman, G. L., Mueller, D. S., Leitz, R. A., Nickell, C. D., and Pedersen, W. L. 1998. Yield and seed quality of soybean 
cultivars infected with Sclerotinia sclerotiorum. Plant Dis. 82:826-829.

13. Kerr, E. D., Steadman, J. R., and Nelson, L. A. 1978. Estimation of white mold disease reduction of yield and yield components of dry edible beans. Crop Sci. 18:275-279.

14. Lamey, H. A. 2003. The status of Sclerotinia sclerotiorum on canola in North America. Proc. 2003 Sclerotinia Initiative Annual Meeting, Bloomington, $\mathrm{MN}$.

15. McLean, D. M. 1958. The role of dead flower parts in infection of certain crucifers by Sclerotinia sclerotiorum (Lib.) de Bary. Plant Dis.
Rep. 42:663:666.

16. Morral, R. A. A., Dueck, J., and Verma, P. R. 1984. Yield losses due to Sclerotinia stem rot in western Canadian rapeseed. (Abstr.) Can. J. Plant Pathol. 6:265.

17. Tsror, L. (Lahkim), Hazanovsky, M., Mordechi-Lebiush, S., and Sivan, S. 2001. Aggressiveness of Verticillium dahliae isolates from different vegetative compatibility groups to potato and tomato. Plant Pathol. 50:477-482.

18. Yang, X. B., Lundeen, P., and Uphoff, M. D. 1999. Soybean varietal response and yield loss caused by Sclerotinia sclerotiorum. Plant Dis.
83:456-461.

19. Zhao, J., Peltier, A. J., Meng, J., Osborn, T. C., and Grau, C. R. 2004. Evaluation of Sclerotinia stem rot resistance in oilseed Brassica napus using a petiole inoculation technique under greenhouse conditions. Plant Dis. 88:1033-1039.

20. Zhou, Y., Fitt, B. D. L., Welham, S. J., Evans, N., and Gladders, P. 2000. Effects of stem canker (Leptosphaeria maculans) and light leaf spot (Pyrenopeziza brassicae) on yield of winter oilseed rape (Brassica napus) in southern England. Plant Pathol. 49:487-497. 